\title{
Prevalence and Risk Factors of Hypertension in Type 2 Diabetics in Benin
}

\author{
Daniel Amoussou-Guenou ${ }^{1,2}$, Armand Wanvoegbe ${ }^{1,3^{*}}$, Anthelme Agbodandé2, \\ Alihonou Dansou ${ }^{3}$, Yessoufou Tchabi ${ }^{2}$, Yasmine Eyissè ${ }^{2}$, \\ Arnaulde Amoussou-Guenou Fandi ${ }^{4}$, Latif Moussé ${ }^{2}$ \\ ${ }^{1}$ Banque d'insuline, Cotonou, Benin \\ ${ }^{2}$ Polyclinique Atinkanmey, Cotonou, Benin \\ ${ }^{3}$ CHUD-OP, Porto-Novo, Benin \\ ${ }^{4}$ Clinique d'Akpakpa, Cotonou, Benin \\ Email:danielamousguen@yahoo.fr, “wafinarm@yahoo.fr, agbotem@yahoo.fr, alihonoud87@yahoo.fr, \\ youftchabi@yahoo.fr,minayisse@hotmail.com,aarnaulde@yahoo.fr,victorymousse@yahoo.fr
}

Received 18 June 2015; accepted 25 October 2015; published 28 October 2015

Copyright (C) 2015 by authors and Scientific Research Publishing Inc.

This work is licensed under the Creative Commons Attribution International License (CC BY). http://creativecommons.org/licenses/by/4.0/

(c) (i) Open Access

\section{Abstract}

Background: Couple High Blood Pressure (HBP)-Diabetes is a morbid association and a public health problem. The aim of this study was to determine the actual epidemiological profile of HBP in type 2 diabetic. Methods: A cross-sectional, prospective, descriptive and analytical study was conducted at Banque d'insuline of Cotonou, Polyclinique Atinkanmey and CHUD-Ouémé-Plateau. The study took place over a period of 06 months from March 01 to August 30, 2014. The study included patients with type 2 diabetes mellitus seen at consultation who agreed to participate in the study. Results: The survey involved 400 individuals. Among them, $34 \%$ were male and the sex ratio was 0.48 . The mean age was $55.6 \pm 10.3$ years (range $28-87$ years). The prevalence of hypertension in type 2 diabetic patients was $70 \%$. The risk factors significantly associated with HBP were age above 55 years $(p=0.000)$, abdominal obesity $(p=0.036)$, a diabetes duration above 10 years $(p=0.009)$. Complications significantly associated with HBP were stroke $(p=0.013)$ and diabetic foot $(p=0.044)$. Conclusion: HBP-type 2 Diabetes association is frequent in Benin.

\section{Keywords}

Diabetes, Prevalence, Risk Factors, Benin

\footnotetext{
${ }^{*}$ Corresponding author.
}

How to cite this paper: Amoussou-Guenou, D., Wanvoegbe, A., Agbodandé, A., Dansou, A., Tchabi, Y., Eyissè, Y., Fandi, A.A.-G. and Moussé, L. (2015) Prevalence and Risk Factors of Hypertension in Type 2 Diabetics in Benin. Journal of Diabetes Mellitus, 5, 227-232. http://dx.doi.org/10.4236/jdm.2015.54027 


\section{Introduction}

Diabetes mellitus (DM) represents a global public health challenge. Its prevalence particularly the prevalence of type 2 diabetes mellitus is improving in the world.

DM affects 381.8 million persons in the world according to IDF estimations in 2013 [1]. IDF estimates that the number of diabetics will reach 591.9 million in 2035, a 55.0\% ascension [1]. Complications linked with that important risk factor will also increase because of the rise of its principal risk factor as obesity. The last obesity risk of HBP worsens the prognosis of diabetic patient by increasing the cardiovascular risk and chronic complications [2]. HBP represents a very frequent co-morbidity, affecting $20 \%$ to $60 \%$ of diabetics in the world [3]. Detection and treatment of HBP in diabetic patients are the more effective measures for prevention of related complications. The aim of this study was to determine the actual epidemiological profile of HBP in type 2 diabetic in Benin.

\section{Patients and Methods}

\subsection{Framework and Nature of the Study}

This cross-sectional, prospective, descriptive and analytical study was performed at Banque d'insuline of Cotonou, Polyclinique Atinkanmey and CHUD-Ouémé-Plateau. The study took place over a period of 06 months from Marsh 01 to August 30, 2014.

Created in January 1996, "Banque d'insuline" is the main center of diagnosis and ambulatory follow-up of diabetes mellitus in Cotonou. "Polyclinique Atinkanmey" is a private hospital in Cotonou where several specialist doctors carry out medical consultations. CHD OP is the Teaching Hospital of Porto-Novo City.

\subsection{Studied Population and Data Collection}

Were included, the type 2 diabetes followed as outpatients in the different centers studied.

We have included all type 2 diabetics who were consulted by diabetologists who participate to the study (two diabetologists).

During the six months that the study lasted, 400 people were included.

Included Patients were assessed using a survey form designed for this purpose. The clinical records of these patients were also used for the collection of additional data.

Blood pressure was taken in all patients using an electronic sphygmomanometer $\left(\mathrm{OMRON}^{\circledR}\right.$ Blood Pressure Monitor) after five minutes of rest.

\subsection{Studied Variables}

Were studied:

- Socio-demographic characteristics: age, sex, occupation, place of residence, marital status;

- Tensional Profile: hypertension was defined by the blood pressure higher or equal to $140 / 90 \mathrm{mmHg}$, or prehypertension;

- Obesity: were considered obese people with BMI $\geq 30 \mathrm{~kg} / \mathrm{m}^{2}$;

- Abdominal obesity: abdominal obesity was defined using IDF 2005 standards (waist circumference $\geq 94 \mathrm{~cm}$ in Men and $\geq 80 \mathrm{~cm}$ in Women);

- Characteristic of type 2 diabetes: duration of diabetes, diabetes imbalance;

- Complications or other associated risk factors: dyslipidemia, micro albuminuria, diabetic neuropathy, diabetic retinopathy, stroke, diabetic foot, ischemia cardiopathy.

\subsection{Statistical Analysis}

Data were entered and analyzed using SPSS 18.0 software. Categorical variables were expressed as a percentage and quantitative variables averaged together with a standard deviation.

The relation between HBP and investigated factors was studied by calculating the Odd Ratio (OR) with 95\% confidence interval.

We used the Chi-square test for the comparison of the percentages. A $p$ value $<0.05$ was considered significant. 


\section{Results}

\subsection{General Characteristics}

Women represent $66 \%$ of the study population. Sex-ratio is 0.52 . Mean age of patients was $55.6 \pm 10.3$ years with extremes of 28 to 87 years. Three hundred and eighty four patients (95\%) lived in urban city. Customers are the more represented with a $52.5 \%$ proportion. Three hundred and nineteen patients (79.8\%) lived in couple. The diabetes was balanced (HbA1c $<7 \%$ ) in $31.28 \%$ of 243 patients who tested HbA1c.

\subsection{Frequency of HBP}

Frequency of HBP by measure at consultation in diabetic patients was $70 \%$ (see Table 1).

\subsection{Risk Factors (Table 2)}

1) Gender

Gender would not be a factor related to HBP occurrence in type 2 diabetics $(p=0.059)$.

2) Age

Age above 55 years look significantly associated with occurrence of HBP in type 2 diabetics $(p=0.000)$. Frequency of HBP in diabetic patients aged less than 55 years was at $50.5 \%$ while it was at $86.2 \%$ diabetics aged above 55 years.

3) Seniority diabetes

The diabetes duration vary from 1 year to 33 years with a mean duration at $8.27 \pm 6.78$ years. The older is the diabetes, the higher is the risk to develop HBP. The frequency of HBP in diabetic who has less than 10 years of diabetes duration was at $64.1 \%$. Between $10-20$ years duration of diabetes, it was at $77.3 \%(p=0.009)$. Frequency of HBP in type 2 diabetic who has more than 20 years of diabetes duration was at $91.7 \%$. $(p=0.006)$.

4) Abdominal obesity

Abdominal obesity is significantly associated with occurrence of HBP in type 2 diabetics $(p=0.036)$. The frequency of HBP in diabetics with abdominal obesity was at $71.8 \%$ while it was at $57.1 \%$ in those without abdominal obesity.

5) Dyslipidemia

Dyslipidemia do not feel to be associated with occurrence of HBP in type 2 diabetics $(p=0.426)$.

6) Diabetes imbalance

Diabetes imbalance do not seem to influence occurrence of HBP in type 2 diabetics $(p=0.198)$.

7) Degenerative complications of diabetes

Among degenerative complications of diabetes only stroke $(p=0.013)$ and diabetic foot $(p=0.044)$ seem to be linked with HBP in our study.

\section{Discussion}

There was preeminence of female diabetics $(66 \%)$ in our study population with sex-ratio at 0.52 . The result was comparable with Jimoh et al.'s (62\%) [4] and Adebisi et al.'s (60\%) in Nigeria [5]. This female preeminence is probably explained by a more marked care of female than male about health. Male would consult less often for silent disease like diabetes mellitus and HBP. Preeminence in male was noticed by Dibia in Nigeria [6].

Mean age of patients was at $55.6 \pm 10.3$ years with extremes of 28 to 87 years. Two hundred and eighteen patients $(54.5 \%)$ were older than 55 years. This mean age in our study is similar to those of Dibia in Nigeria (58.5 years) [6], Ralison et al. in Madagascar (51 years) [7] and Lokrou et al. in Ivory Cost (49.67 years) [8].

Table 1. Prevalence of HBP in diabetics.

\begin{tabular}{ccc}
\hline Tensional Profile & Number & Percentage \\
\hline HBP & 280 & $\mathbf{7 0 \%}$ \\
No HBP & 120 & $30 \%$ \\
Total & 400 & $100 \%$ \\
\hline
\end{tabular}


Table 2. Summary of relation between HBP and investigated factors.

\begin{tabular}{|c|c|c|c|c|c|c|}
\hline \multirow{2}{*}{ Factors } & & \multicolumn{2}{|c|}{ HBP } & \multirow{2}{*}{ OR } & \multirow{2}{*}{ IC $(95 \%)$} & \multirow{2}{*}{$p$} \\
\hline & & Present & Absent & & & \\
\hline \multirow{2}{*}{ Sex } & Male & 87 & 49 & \multirow{2}{*}{0.6} & \multirow{2}{*}{$0.4-1.0$} & \multirow{2}{*}{0.059} \\
\hline & Female & 193 & 71 & & & \\
\hline \multirow[b]{2}{*}{ Age } & $<55$ years & 92 & 90 & \multirow[b]{2}{*}{6.1} & \multirow[b]{2}{*}{$3.8-9.3$} & \multirow[b]{2}{*}{$\underline{0.000}$} \\
\hline & $\geq 55$ years & 118 & 30 & & & \\
\hline \multirow{2}{*}{ Abdominal obesity } & Present & 252 & 99 & \multirow{2}{*}{1.9} & \multirow{2}{*}{$1.0-3.5$} & \multirow{2}{*}{$\underline{0.03}$} \\
\hline & Absent & 28 & 21 & & & \\
\hline \multirow{3}{*}{ BMI } & $<25$ & 63 & 26 & 1 & & \\
\hline & $25-29.99$ & 102 & 55 & 0.8 & $0.4-1.3$ & 0.350 \\
\hline & $\geq 30$ & 115 & 39 & 1.2 & $0.8-2.2$ & 0.510 \\
\hline \multirow{2}{*}{ Dyslipidemia } & Present & 83 & 28 & \multirow{2}{*}{1.3} & \multirow{2}{*}{$0.7-2.3$} & \multirow{2}{*}{0.426} \\
\hline & Absent & 72 & 31 & & & \\
\hline \multirow{3}{*}{$\begin{array}{c}\text { Duration of } \\
\text { diabetes }\end{array}$} & $<10$ years & 159 & 89 & 1 & & \\
\hline & $10-20$ years & 99 & 29 & 1.9 & $1.2-3.1$ & $\underline{0.009}$ \\
\hline & $>20$ years & 22 & 02 & 6.2 & $1.4-26.8$ & $\underline{0.006}$ \\
\hline Diabetes & $\mathrm{HbAlc} \geq 7$ & 117 & 50 & \multirow{2}{*}{0.6} & \multirow{2}{*}{$0.3-1.2$} & \multirow{2}{*}{0.198} \\
\hline imbalance & $\mathrm{HbA} 1 \mathrm{c}<7$ & 60 & 16 & & & \\
\hline \multirow[b]{2}{*}{ Micro albuminuria $24 \mathrm{~h}$} & Present & 57 & 14 & \multirow[b]{2}{*}{1.5} & \multirow[b]{2}{*}{$0.7-3.2$} & \multirow[b]{2}{*}{0.380} \\
\hline & Absent & 65 & 24 & & & \\
\hline \multirow{2}{*}{ Diabetic neuropathy } & Présent & 214 & 90 & & & \\
\hline & Absent & 66 & 30 & 1.1 & $0.1=1.0$ & - 0.10 \\
\hline & Present & 42 & 08 & & & \\
\hline Diabetic retinopathy & Absent & 94 & 37 & 2.1 & $0.9-4.8$ & 0.131 \\
\hline & Present & 14 & 00 & & & \\
\hline Nitume & Absent & 266 & 120 & 1.4 & $1.5-1.5$ & $\underline{0.015}$ \\
\hline & Present & 23 & 03 & & & \\
\hline Dlabetic root & Absent & 257 & 117 & 3.4 & $1.0-11.1$ & $\underline{0.044}$ \\
\hline & Present & 08 & 02 & & & \\
\hline Ischemia cardiopathy & Absent & 97 & 37 & 1.5 & $0.3-7$ & 0.729 \\
\hline
\end{tabular}

HbA1c: glycated hemoglobin; OR: odd ratio; CI: confidence interval.

The prevalence of HBP in type 2 diabetics in our study was at $70 \%$. This high frequency is similar to those reported by Howards et al. in 2006 in Canada (70\%) [9], Dibia in 2009 in Nigeria (71.6\%) [6], Lokrou et al. in 2009 in Ivory Cost (76.82\%) [8] and Tanguy et al. in 2012 in Limoges (75\%) [10].

Contrary to our study, other authors reported lower frequencies of HBP in type 2 diabetes. In this way, Dembele et al. reported 16.7\% in Bamako in 2000 [11], Ralison et al. reported 39.63\% in Madagascar in 2007 [7], Ntyonga-Pono reported 40.67\% in Gabon in 1996 [12] and Louda et al. reported 54.4\% in Marocco in 2010 [13]. This difference of frequency would be linked to the methodology used by the authors. In fact, those studies were 
retrospective and some authors used old WHO criterions of diagnosis for HBP (160/95 mmHg). It could explain the low frequency of HBP in diabetics in those studies.

We didn't identify gender as risk factor for HBP in type 2 diabetes in our study $(p=0.059)$, but the frequency of HBP in female was higher (73.1\%) than in male (64\%). Dibia didn't identify gender as risk factor for HBP in type 2 diabetes [6].

Adverse results were reported by Dembele et al. [11] and Ralison et al. [7] who identified female sex as risk factor for HBP in type 2 diabetes.

Age was identified to a risk factor associated to HBP in type 2 diabetes in our study $(p=0.000)$. Occurrence of HBP increased with age. Other authors reported similar conclusion. In this way, Dibia reported that $67 \%$ of diabetics with hypertension had age range between 51 and 70 years [6]; Aassri et al. found that HBP and diabetes association was significant between 66 and 69 years [14]; Ralison et al. found a pic of HBP in type 2 diabetics above 50 years and particularly between 60 and 69 years [7]; according to Khochtali et al. in Tunisia, 77\% of diabetics above 65 years had hypertension [15]. This fact would be due to modifications of vascular system observed with age. In effect, an alteration and a relative reduction of elastic fibers occur and are replaced by collagen tissue in arteries wall. This evolution induces more rigidity of arteries contributing to elevate blood pressure.

In our study, the duration of diabetes was a factor associated with hypertension in type 2 diabetes. This trend was confirmed by Dibia in Nigeria [6] and Motala in South Africa [16]. This result may be related to chronic hyperglycemia resulting in endothelial suffering leading to thickening of the arterial wall and to a rise in blood pressure later.

We found that abdominal obesity was significantly associated with the occurrence of hypertension in type 2 diabetic patients $(p=0.036)$. Indeed in our study, the frequency of hypertension in type 2 diabetics with abdominal obesity was $71.9 \%$ against $57.1 \%$ among those who did not have abdominal obesity. This same observation was made in the general population by Gordon et al. [17]. The author has dismantled that abdominal obesity is a risk factor associated with the occurrence of hypertension and type 2 diabetes.

The result of our study could be explained by the fact that type 2 diabetes was usually part of metabolic syndrome.

Our results showed no correlation between dyslipidemia and hypertension in type 2 diabetics.

Conflicting results have been reported in Japan, where a significant correlation is found between the HDL hypocholesterolemia and the occurrence of hypertension in diabetic hypertensive by Miyagi et al. [18]. This same observation was made in Morocco by Diyane et al. [19]. This could be related to the fact that all patients were unable to make or cholesterol and triglycerides.

Contrary to some published data [10] [19], our study did not identify any microangiopathy as a factor associated with hypertension in type 2 diabetics.

According to the results of our study, history of stroke was found to be correlated with hypertension in type 2 diabetics because all diabetic patients with stroke had hypertension $(p=0.013)$. This observation corroborates those of Diyane et al. [19] and Tanguy et al. [10]. In addition, a meta-analysis [20] published in 2011 showed that in diabetic type 2, reducing the risk of stroke was proportional to the reduction in SBP.

We also identified the diabetic foot as a factor associated with hypertension in type 2 diabetics. Therefore, special monitoring of the feet will be indicated in diabetic patients with hypertension.

\section{References}

[1] Guarignata, L., Whiting, D.R., Beagley, J., Linnenkamp, U., Hambleton, I., Cho, N.H., et al. (2013) Global Estimates of Diabetes Prevalence in Adults for 2013 and Projection for 2035 for the IDF Diabetes Atlas. Diabetes Research and Clinical Practice, 103, 137-149.

[2] Laboureau-Soares Barbosa, S., Bouhanick, B. and Marre, M. (2000) Diabetic Hypertension. Encyclopédie MédicoChirurgicale, Endocrinologie-Nutrition, 10-366-J-10, 7 p.

[3] Racine, N. (2003) High Blood Pressure in Diabetic Patients: How to Evaluate and Treat? Le Clinicien, 18, 95-102.

[4] Jimoh, K., Adediran, O., Agboola, S., et al. (2008) A Study of Correlation between Derived and Basic Anthropometric Indices in Type 2 Diabetes Mellitus. The Internet Journal of Endocrinology, 5, 1-6.

[5] Adebisi, S.A., Oghagbon, E.K. and Jimoh, A.K. (2003) Glycated Haemoglobin and Associated Variables in Diabetics: Ilorin Experience. West African Journal of Medicine, 22, 318-320.

[6] Dibia, O.G. (2009) Hypertension in Patients with Type 2 Diabetes Followed in CHU Obafemi Awolowo Ile-Ife (Osun State) in Nigeria. Ph.D. Dissertation, Faculty of Medicine, Pharmacy and Dentistry, Bamako. 
[7] Ralison, F., Aboudou II, Raharimanana, R.N., et al. (2010) Epidemiological Profile of Diabetic Hypertensive Hospitalized in Internal Medicine at the University Hospital of Mahajanga Madagascar. Revue électronique en sciences de la santé, 1, 28-35.

[8] Lokrou, A. And Diallo, M.M. (2010) BP Level of Diabetics. Diabetes \& Metabolism, 36, A53. http://dx.doi.org/10.1016/S1262-3636(10)70207-X

[9] Howards, J.N.B. and Bower Kmb, W.P. (2006) Factors Influencing the Management of Hypertension in Type 2 Diabetes. Canadian Journal of Diabetes, 30, 38-45. http://dx.doi.org/10.1016/S1499-2671(06)01004-5

[10] Tanguy, B. and Aboyans, V. (2012) The Management of the Diabetic Hypertensive Patient. Réalités Cardiologiques, 290, 49-53.

[11] Dembele, M., Sidibe, A.T., Traore, H.A., et al. (2000) Association HBP-Diabetes Mellitus in the Internal Medicine Department of the Hospital Point G BAMAKO. Médecine d'Afrique Noire, 47, 276-280.

[12] Ntyonga-Pono, M.P. (1996) High Blood Pressure in Diabetic Gabonese. Médecine d' Afrique Noire, 43, 434-437.

[13] Louda, F., Addi, H., Hallab, L., et al. (2010) Hypertension and Type 2 Diabetes. Diabetes \& Metabolism, 36, A53. http://dx.doi.org/10.1016/S1262-3636(10)70208-1

[14] Aassri, H.E., Mghari, G.E. and Ansari, N.E. (2014) Patients with Type 2 Diabetes with Hypertension: Do They Prefer to Treat Diabetes or High Blood Pressure? Pan African Medical Journal, 17, 193.

[15] Khochtali, I., Hamza, N., Baba, A., et al. (2010) Macrovascular Complication in Elderly Diabetic. Diabetes \& Metabolism, 36, A53. http://dx.doi.org/10.1016/S1262-3636(10)70206-8

[16] Motala, A.A., Pirie, F.J. and Aaoma, G.E. (2001) Micro Vascular Complications in South African Patients with Long-Duration Diabetes Mellitus. SAMJ, 91, 987-992.

[17] Gordon, W.M. (2006) The Obesity Epidemic: Update on Global Cardiometabolic Risk. Actualités scientifiques, 82, 16.

[18] Miyagi, T., Muratani, H., Kimura, Y., et al. (2002) Increase in Pulse Pressure Relates to Diabetes Mellitus and Low HDL Cholesterol, but Not to Hyperlipidemia in Hypertensive Patients Aged 50 Years or Older. Hypertension Research, 25, 335-341. http://dx.doi.org/10.1291/hypres.25.335

[19] Diyane, K., Ansari, N.E., Mghari, G.E., et al. (2013) The Characteristics of the Association of Type 2 Diabetes and Hypertension in the Elderly 65 Years and Older. Pan African Medical Journal, 14, 100.

[20] Bangalore, S., Kumar, S., Lobach, I., et al. (2011) Blood Pressure Targets in Subjects with Type 2 Diabetes Mellitus/ Impaired Fasting Glucose: Observations from Traditional and Bayesian Random-Effects Meta-Analyses of Randomized Trials. Circulation, 123, 799-810. http://dx.doi.org/10.1161/CIRCULATIONAHA.110.016337 